\title{
Expression of UCA1 and MALAT1 long-chain non-coding RNAs in esophageal squamous cell carcinoma tissues is predictive of patient prognosis
}

Kai Kang ${ }^{1}$, Yong-Hua Huang ${ }^{2}$, Hai-Peng Li², Shu-Mei Guo ${ }^{1}$

\author{
${ }^{1}$ Department of Gastroenterology, the First Hospital of Yulin City, Yulin, Shaanxi \\ Province, China \\ 2Department of Gastroenterology, Xingyuan Hospital of Yulin City, Shaanxi Province, \\ Yulin, Shaanxi Province, China \\ ${ }^{3}$ Department of Thoracic Surgery, Central Hospital of Baoji City, Baoji, Shaanxi \\ Province, China
}

Submitted: 10 December 2016

Accepted: 18 February 2017

Arch Med Sci 2018; 14, 4: 752-759

DOI: https://doi.org/10.5114/aoms.2018.73713

Copyright $\odot 2018$ Termedia \& Banach

\section{Abstract}

Introduction: The long non-coding RNAs (IncRNAs) urothelial cancer associated 1 (UCA1) and metastasis associated lung adenocarcinoma transcript 1 (MALAT1) are known to impact cancer cell regulation. The aim of the present study was to determine the relationship between the expression of these IncRNAs in esophageal squamous cell carcinoma (ESCC) tissues and disease prognosis.

Material and methods: The expression of UCA1 and MALAT1 IncRNAs was assessed in ESCC and adjacent carcinoma tissues $(5 \mathrm{~cm}$ away from the tumor) and evaluated in relation to overall survival (OS) and disease-free survival (DFS) of patients. This prospective study included 100 ESCC patients who were admitted to the First Hospital of Yulin City between January 2007 and January 2014.

Results: The expression levels of UCA1 and MALAT1 IncRNAs in ESCC tissues were significantly higher than those in adjacent carcinoma tissues, and there were statistically significant differences in TNM staging between the patients with high IncRNA expression and low IncRNA expression. The OS and DFS of patients with high UCA1 and MALAT1 IncRNA expression levels were significantly shorter than those with low expression levels. Furthermore, the OS and DFS of ESCC patients appeared to be correlated with TNM staging.

Conclusions: These results imply that the up-regulation of UCA1 and MALAT1 InCRNAs in ESCC tissues can impact the degree of tumor progression and is predictive of postoperative survival. Therefore, the expression levels of these IncRNAs can be used as measurement indexes to determine the prognosis of ESCC patients.

Key words: long non-coding RNA, urothelial cancer associated 1, metastasis associated lung adenocarcinoma transcript 1, esophageal squamous cell carcinoma, prognosis, survival analysis.

\section{Introduction}

Esophageal carcinoma $(E C)$ is one of the most serious malignant tumors of the digestive system. The morbidity rate of EC ranks eighth and

\author{
Corresponding authors: \\ Hai-Peng Li \\ Department \\ of Thoracic Surgery \\ Central Hospital of Baoji City \\ No. 8 at Jiangtan Road \\ Baoji 721008 \\ Shaanxi Province, China \\ E-mail: cyb8888168@126.com \\ Shu-Mei Guo \\ Department of \\ Gastroenterology \\ the First Hospital of Yulin City \\ High-tech District \\ Yulin 719000 \\ Shaanxi Province, China \\ E-mail: pyp721@163.com
}


the mortality rate ranks sixth among malignant tumors worldwide [1, 2]. Two histologic types are typical among EC patients: esophageal adenocarcinoma (EAC) and esophageal squamous cell carcinoma (ESCC). Patients in Western countries predominantly develop EAC, while Chinese patients typically develop ESCC. About $50 \%$ of ESCCS are formed in the middle esophagus [3]. Surgical removal is currently the most common treatment for ESCC, but the prognosis after a radical operation is less than ideal. According to recent studies, surgical treatment only gives ESCC patients at stages IIA-III a 5-year survival rate of 20-34\% and fails to effectively eliminate distal metastasis and local tumor recurrence [4]. Currently, the TNM classification of malignant tumors serves as the primary basis for determining ESCC prognosis. The lack of objective quantitative indicators to accurately predict prognosis lends itself to opportunities for improvement [5].

Long noncoding RNAs (IncRNA) have emerged as influential factors in the occurrence and development of tumors. LncRNAs are more than 200 nucleotides in length and in most cases are produced by RNA polymerase II and undergo post-transcriptional modifications, such as capping and intron splicing. LncRNA genes usually contain few introns and have low levels of transcription, low conservation among different species, and in most cases have spatiotemporal expression specificity $[6,7]$. Although this type of RNA does not have protein-encoding function, it can regulate gene expression at the chromosome, chromatin, transcriptional, and post-transcriptional levels and exerts significant regulatory effects through, inter alia, genomic imprinting, cell differentiation, immune reactions, tumor occurrence, and embryonic stem cell multi-potency. Recent studies have shown that multiple IncRNAs can produce small molecular peptides through transcription to become the driving force for the generation of new proteins [8-10]. In multiple large-scale screening studies, the expression of over 100 IncRNAs in ESCC tissues has been found to be altered. The abnormal expression of IncRNAs is mostly present during the evolution of highly differentiated intraepithelial neoplasia into invasive carcinoma, reflecting the important role of IncRNA in the development of ESCC [11-13].

Two genes known to encode IncRNAs are urothelial cancer associated 1 (UCA1) and metastasis associated lung adenocarcinoma transcript 1 (MALAT1). Li et al. reported that the relative level of UCA1 was significantly higher in ESCC tissues compared to the adjacent non-tumor tissue, and remarkably higher expression of UCA1 was found in esophageal cancer cell lines compared with the immortalized esophageal epithelial cell line NE1
[14], and it was found to be deregulated in cisplatin-resistant cells compared with their parent cells [15]. MALAT1 was over-expressed in $46.3 \%$ of ESCC tissues. The enhanced MALAT1 expression levels were positively correlated with clinical stages, primary tumor size, and lymph node metastasis, and inhibition of MALAT1 suppressed tumor proliferation in vitro and in vivo, as well as the migratory and invasive capacity [16]. Furthermore, silencing of MALAT1 could significantly suppress the proliferation of ESCC cells through the arrest of the G2/M cell cycle, which may be due to MALAT1-mediated up-regulation of p21 and p27 expression and the inhibition of B-MYB expression [17]. Recently, animal experiments showed that knockdown of MALAT1 decreased tumor formation and improved survival [18]. Here, we describe the relationship between the expression of UCA1 and MALAT1 InCRNAs in ESCC tissues and the associated prognosis.

\section{Material and methods}

\section{Tissues samples}

The tumor tissues and para-carcinoma tissues were taken from 100 ESCC patients who were admitted to the First Hospital of Yulin City between January 2007 and January 2014 and treated as participants of this case-control prospective study.

Table I. Clinical characteristics of study participants

\begin{tabular}{|c|c|c|}
\hline Characteristics & $\begin{array}{l}\text { Number } \\
\text { of cases }\end{array}$ & Percentage \\
\hline \multicolumn{3}{|l|}{ Gender: } \\
\hline Male & 75 & 75.0 \\
\hline Female & 25 & 25.0 \\
\hline \multicolumn{3}{|l|}{ Age [years]: } \\
\hline$\leq 60$ & 68 & 68.0 \\
\hline$>60$ & 32 & 32.0 \\
\hline \multicolumn{3}{|l|}{$\begin{array}{l}\text { Histological } \\
\text { grade: }\end{array}$} \\
\hline $1-2$ & 41 & 41.0 \\
\hline $3-4$ & 59 & 59.0 \\
\hline \multicolumn{3}{|l|}{ TNM stage: } \\
\hline$|-| \mid$ & 73 & 73.0 \\
\hline III & 27 & 27.0 \\
\hline \multicolumn{3}{|l|}{$\begin{array}{l}\text { Pathological } \\
\text { type: }\end{array}$} \\
\hline $\begin{array}{l}\text { Ulcerative } \\
\text { carcinoma }\end{array}$ & 65 & 65.0 \\
\hline Others & 35 & 35.0 \\
\hline \multicolumn{3}{|l|}{$\begin{array}{l}\text { Adjuvant } \\
\text { chemotherapy } \\
\text { or radiotherapy: }\end{array}$} \\
\hline Yes & 59 & 59.0 \\
\hline No & 41 & 41.0 \\
\hline
\end{tabular}


The adjacent carcinoma tissues had been obtained at least $5 \mathrm{~cm}$ away from the tumor. Patients were diagnosed with ESCC based on a postoperative pathological examination. Clinical characteristics of participants are shown in Table I. Patients were monitored after surgery by telephone follow-up or visits to the patient's home, and the total survival (OS) and disease free survival (DFS) status was observed, with OS representing the time from surgery to death or the last follow-up visit and DFS representing the time from the surgery to the local recurrence, distal metastasis, or the last follow-up visit. This study was approved by the Ethics Committee of the First Hospital of Yulin City, and informed consent was given by all participants.

\section{Detection of IncRNAs}

Expression levels of UCA1 and MALAT1 IncRNAs were detected in the tumor tissues and para-carcinoma tissues as follows: total RNA was extracted by RNAiso Plus (code no. 9108Q; TaKaRa Biotechnology Limited Company, Dalian, China), the PrimeScript RT reagent kit (code no. RR037A, TaKaRa Bio.) was used to transcribe and synthesize CDNA, and real-time quantitative PCR (q-RT PCR) was used to quantify target IncRNA with $18 \mathrm{~S}$ as the internal reference. The primer sequences are shown in Table II. The total reaction volume was $10 \mu \mathrm{l}$, including of $5 \mu \mathrm{l}$ of SYBR Green I Master Mix, $1 \mu \mathrm{l}$ of RNAiso Plus, $0.6 \mu \mathrm{l}$ of forward primers $(10 \mu \mathrm{mol} / \mathrm{l}), 0.6 \mu \mathrm{l}$ of reverse primers $(10 \mu \mathrm{mol} / \mathrm{l}), 1 \mu \mathrm{l}$ of CDNA, and $1.8 \mu \mathrm{l}$ of $\mathrm{dH}_{2} \mathrm{O}$ deionized water. The reaction conditions were: pre-degeneration at $95^{\circ} \mathrm{C}$ for $10 \mathrm{~s}, 95^{\circ} \mathrm{C}$ for $5 \mathrm{~s}, 60^{\circ} \mathrm{C}$ for $5 \mathrm{~s}$, and $72^{\circ} \mathrm{C}$ for $31 \mathrm{~s}$, and amplification for 40 cycles. The differences between the target IncRNA cycle threshold values (Ct values) and $18 \mathrm{~S} C t$ value were determined $(\Delta C t)$ and the $2^{-\Delta \Delta C t}$ method was used to determine the relative expression of target IncRNA. Compared to the mean expression levels in ESCC tissues, the patients were categorized as having high UCA1 expression, low UCA1 expression, high MALAT1 expression, and low MALAT1 expression.

\section{Statistical analysis}

Data were analyzed using SPSS 19.0 statistical software (IBM, Armonk, NY). Measurement data were expressed as mean \pm standard deviation and an independent sample $t$ test was used to compare groups. Kaplan-Meier survival analysis was used to compare OS and DFS and the logrank test was used to determine statistical significance. The Cox risk model was used to analyze factors influencing OS and DFS. A $p$ level $<0.05$ indicated statistical significance.

\section{Results}

\section{UCA1 and MALAT1 IncRNAs are higher in ESCC tissues than in para-carcinoma tissues}

The relative expression levels of UCA1 were $0.485 \pm 0.248$ in ESCC tissues and $0.199 \pm 0.122$ in adjacent carcinoma tissues, with a significant difference ( $t=10.348, p<0.05)$. Similarly, the expression levels of MALAT1 were $3.842 \pm 0.415$ in ESCC tissues and $1.451 \pm 0.136$ in adjacent carcinoma tissues, with a significant difference $(t=$ 54.750, $p<0.05)$.

\section{UCA1 and MALAT1 IncRNA expression is correlated with TNM staging in ESCC tissues}

Patients were categorized as having high UCA1 expression (49 cases), low UCA1 expression (51 cases), high MALAT1 expression (50 cases), and low MALAT1 expression (50 cases) compared to the mean expression levels in ESCC tissues. Clinical characteristics were compared between groups and the difference in TNM staging between the high UCA1 expression group and the low UCA1 expression group as well as between the high MALAT1 expression group and the low MALAT1 expression group was statistically significant $\left(\chi^{2}=12.257,26.839, p<0.05\right)$. The difference in other clinical characteristics was not found to be statistically significant (Tables III and IV).

Table II. Primer sequences of target IncRNA

\begin{tabular}{|llc|}
\hline LncRNAs & Primer & \multicolumn{1}{c|}{ Sequence } \\
\hline UCA1 & Forward & $5^{\prime}$-CTCTCCATTGGGTTCACCATTC-3' \\
\cline { 2 - 3 } MALAT1 & Reverse & $5^{\prime}$-GCGGCAGGTCTTAAGAGATGAG-3' \\
\hline & Forward & $5^{\prime}$-CAGTGGGGAACTCTGACTCG-3' \\
\cline { 2 - 3 } $18 \mathrm{~S}$ & Reverse & $5^{\prime}$-GTGCCTGGTGCTCTCTTAC C-3' \\
\cline { 2 - 3 } & Forward & $5^{\prime}$-CAGCCACCCGAGATTGAGCA-3' \\
\hline
\end{tabular}


Table III. UCA1 IncRNA expression in ESCC tissues and clinical characteristics

\begin{tabular}{|c|c|c|c|c|c|}
\hline Characteristics & $\begin{array}{c}\text { Number of } \\
\text { cases }\end{array}$ & $\begin{array}{l}U C A 1 \text { high } \\
\text { expression } \\
(N=49)\end{array}$ & $\begin{array}{l}U C A 1 \text { low } \\
\text { expression } \\
(N=51)\end{array}$ & $\chi^{2}$ & $P$-value \\
\hline \multicolumn{6}{|l|}{ Gender: } \\
\hline Male & 75 & 35 & 40 & \multirow{2}{*}{0.654} & \multirow{2}{*}{$>0.05$} \\
\hline Female & 25 & 14 & 11 & & \\
\hline \multicolumn{6}{|l|}{ Age [years]: } \\
\hline$\leq 60$ & 68 & 31 & 37 & \multirow{2}{*}{0.990} & \multirow{2}{*}{$>0.05$} \\
\hline$>60$ & 32 & 18 & 14 & & \\
\hline \multicolumn{6}{|l|}{ Histological grade: } \\
\hline $1-2$ & 41 & 22 & 19 & \multirow{2}{*}{0.603} & \multirow{2}{*}{$>0.05$} \\
\hline $3-4$ & 59 & 27 & 32 & & \\
\hline \multicolumn{6}{|l|}{ TNM stage: } \\
\hline$|-| \mid$ & 73 & 28 & 45 & \multirow{2}{*}{12.257} & \multirow{2}{*}{$<0.05$} \\
\hline III & 27 & 21 & 6 & & \\
\hline \multicolumn{6}{|l|}{ Pathological type: } \\
\hline Ulcerative carcinoma & 65 & 33 & 32 & \multirow{2}{*}{0.233} & \multirow{2}{*}{$>0.05$} \\
\hline Others & 35 & 16 & 19 & & \\
\hline
\end{tabular}

Table IV. MALAT1 IncRNA expression in ESCC tissues and clinical characteristics

\begin{tabular}{|c|c|c|c|c|c|}
\hline Characteristics & $\begin{array}{c}\text { Number of } \\
\text { cases }\end{array}$ & $\begin{array}{l}\text { MALAT1 high } \\
\text { expression } \\
(N=50)\end{array}$ & $\begin{array}{l}\text { MALAT1 low } \\
\text { expression } \\
(N=50)\end{array}$ & $\chi^{2}$ & $P$-value \\
\hline \multicolumn{6}{|l|}{ Gender: } \\
\hline Male & 75 & 39 & 36 & \multirow{2}{*}{0.480} & \multirow{2}{*}{$>0.05$} \\
\hline Female & 25 & 11 & 14 & & \\
\hline \multicolumn{6}{|l|}{ Age [years]: } \\
\hline$\leq 60$ & 68 & 36 & 32 & \multirow{2}{*}{0.735} & \multirow{2}{*}{$>0.05$} \\
\hline$>60$ & 32 & 14 & 18 & & \\
\hline \multicolumn{6}{|l|}{ Histological grade: } \\
\hline $1-2$ & 41 & 19 & 22 & \multirow{2}{*}{0.372} & \multirow{2}{*}{$>0.05$} \\
\hline $3-4$ & 59 & 31 & 28 & & \\
\hline \multicolumn{6}{|l|}{ TNM stage: } \\
\hline$|-| \mid$ & 73 & 25 & 48 & \multirow{2}{*}{26.839} & \multirow{2}{*}{$<0.05$} \\
\hline III & 27 & 25 & 2 & & \\
\hline \multicolumn{6}{|l|}{ Pathological type: } \\
\hline Ulcerative carcinoma & 65 & 31 & 34 & \multirow{2}{*}{0.396} & \multirow{2}{*}{$>0.05$} \\
\hline Others & 35 & 19 & 16 & & \\
\hline
\end{tabular}

\section{UCA1 and MALAT1 IncRNA expression in} ESCC tissues is predictive of patient survival

The OS and DFS of patients with high UCA1 and MALAT1 IncRNA expression in ESCC tissues were significantly lower than those of patients with low expression levels $\left(\chi^{2}=4.880,5.894,8.635,8.906\right.$, $p<0.05)$. OS, DFS, and $95 \%$ confidence intervals (CI) are shown in Tables V, VI and VII, and the Kaplan-Meier statistical significance analytic curves are shown in Figure 1.

\section{Multiple factors influence the survival of ESCC patients}

Cox survival models revealed that OS and TNM staging $(H R=2.516)$ were significantly correlated $(p<0.05)$ with UCA1 IncRNA $(H R=1.638)$ and MALAT1 LnCRNA (HR = 1.553) in ESCC patients. In addition, DFS and TNM staging $(H R=2.881)$ were also correlated with UCA1 IncRNA (HR $=1.662)$ and MALAT1 InCRNA (HR =1.713), as shown in Tables VIII and IX. 
A

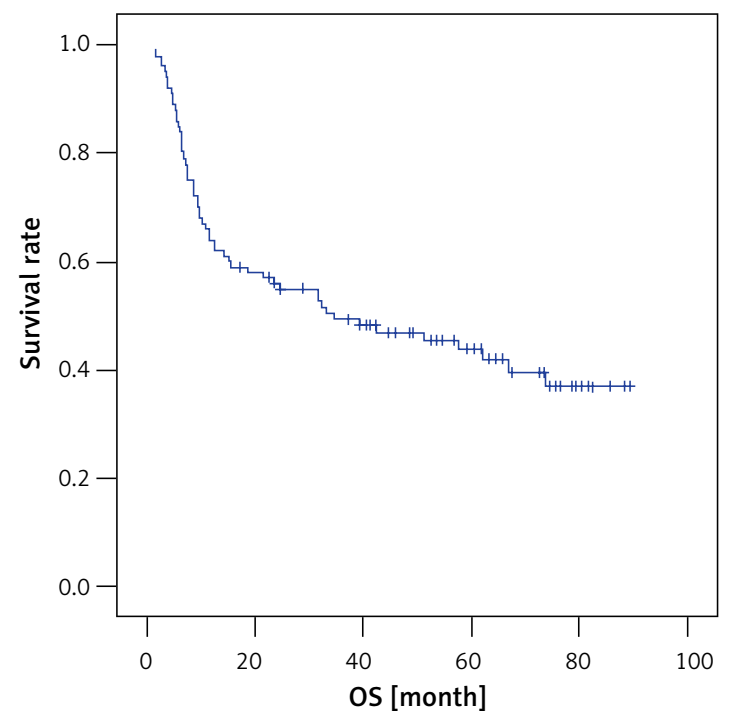

C

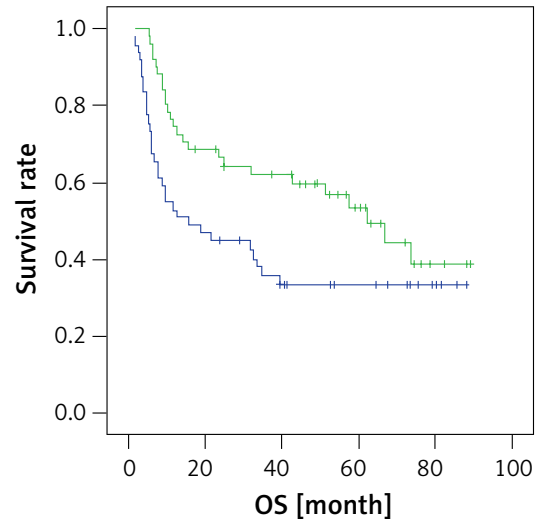

E

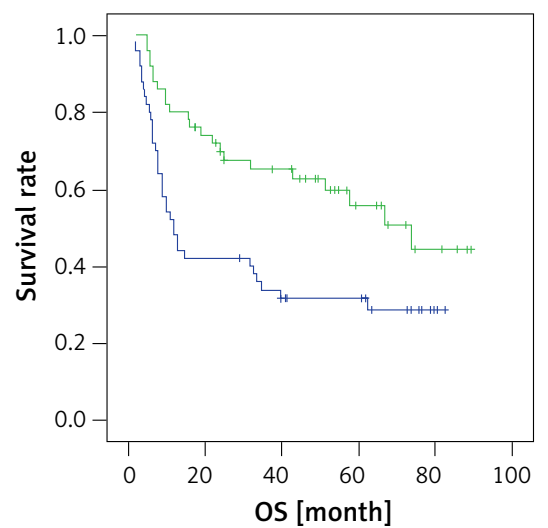

MALAT1

_ High

expression

Low

expression

High

+ expression

- censored

Low

+ expression

- censored
B

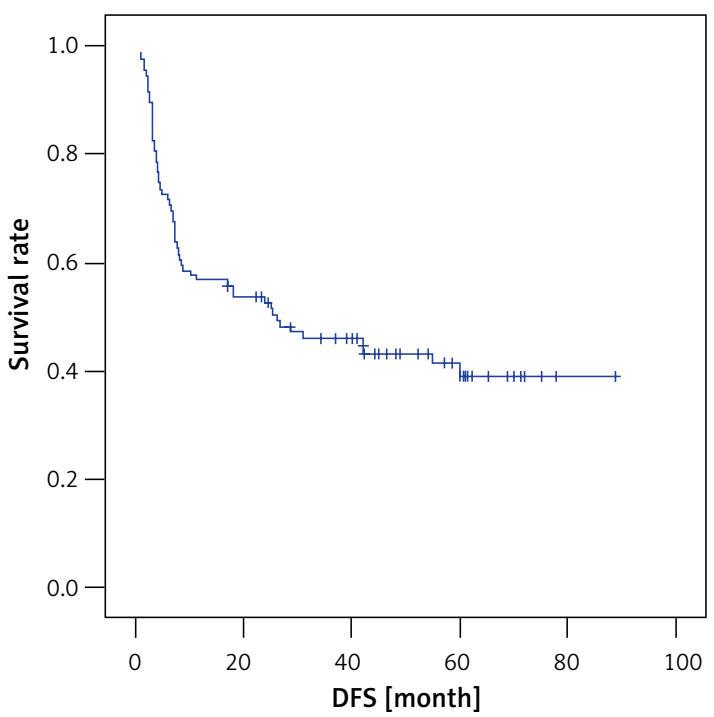

D

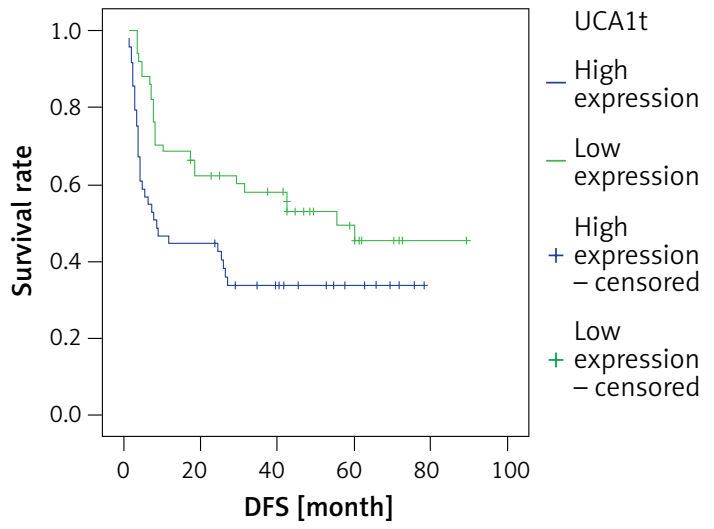

F

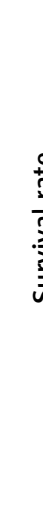

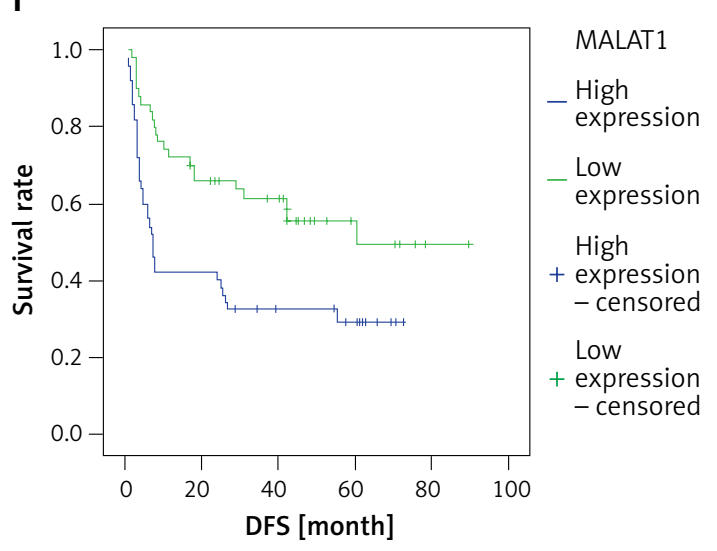

Figure 1. A - Kaplan-Meier survival curve of OS of patients, B - Kaplan-Meier survival curve of DFS of patients, C - Kaplan-Meier survival curve of OS of patients with different UCA1 IncRNA expression levels, D - Kaplan-Meier survival curve of DFS of patients with different UCA1 IncRNA expression levels, E - Kaplan-Meier survival curve of OS of patients with different MALAT1 IncRNA expression levels, F - Kaplan-Meier survival curve of DFS of patients with different MALAT1 InCRNA expression levels 
Table V. OS and DFS of ESCC patients

\begin{tabular}{|lcccc|}
\hline Survival & Estimate & Std. error & \multicolumn{2}{c|}{$95 \% \mathrm{Cl}$} \\
\cline { 4 - 5 } & & & Lower bound & Upper bound \\
\hline OS [month] & 46.069 & 3.815 & 38.591 & 53.547 \\
\hline DFS [month] & 43.457 & 3.996 & 35.625 & 51.288 \\
\hline
\end{tabular}

Table VI. OS and DFS of patients with different UCA1 IncRNA expression levels

\begin{tabular}{|lccccc|}
\hline Groups & Survival & Estimate & Std. Error & \multicolumn{2}{c|}{$95 \% \mathrm{Cl}$} \\
\cline { 5 - 6 } & & & & Lower bound & Upper bound \\
\hline $\begin{array}{l}\text { UCA1 high } \\
\text { expression }\end{array}$ & OS & 53.754 & 5.096 & 43.766 & 63.741 \\
\hline $\begin{array}{l}\text { UCA1 low } \\
\text { expression }\end{array}$ & DFS & 51.636 & 5.403 & 41.046 & 62.225 \\
\cline { 2 - 6 } & OS & 37.538 & 5.365 & 27.023 & 48.052 \\
\hline
\end{tabular}

Table VII. OS and DFS of patients with different MALAT1 IncRNA expression levels

\begin{tabular}{|lccccc|}
\hline Groups & Survival & Estimate & Std. error & \multicolumn{2}{c|}{$95 \% \mathrm{Cl}$} \\
\cline { 5 - 6 } & & & & Lower bound & Upper bound \\
\hline $\begin{array}{l}\text { MALAT1 high } \\
\text { expression }\end{array}$ & OS & 57.089 & 5.136 & 47.022 & 67.156 \\
\hline $\begin{array}{l}\text { MALAT1 low } \\
\text { expression }\end{array}$ & DFS & 54.440 & 5.540 & 43.582 & 65.299 \\
\cline { 2 - 6 } & DFS & 32.999 & 4.760 & 23.670 & 42.329 \\
\hline
\end{tabular}

Table VIII. Multiple factors influence OS in ESCC patients

\begin{tabular}{|lcccc|}
\hline Item & $\beta$ & $\chi^{2}$ & HR & $p$-value \\
\hline TNM stage (stage III) & 0.794 & 5.116 & 2.516 & $<0.05$ \\
\hline UCA1 high expression & 0.436 & 6.025 & 1.638 & $<0.05$ \\
\hline MALAT1 high expression & 0.237 & 4.915 & 1.553 & $<0.05$ \\
\hline
\end{tabular}

Table IX. Multiple factors influence DFS in ESCC patients

\begin{tabular}{|lcccc|}
\hline Item & $\beta$ & $\chi^{2}$ & HR & $p$-value \\
\hline TNM stage (stage III) & 0.662 & 4.628 & 2.881 & $<0.05$ \\
\hline UCA1 high expression & 0.168 & 5.604 & 1.662 & $<0.05$ \\
\hline MALAT1 high expression & 0.339 & 6.113 & 1.713 & $<0.05$ \\
\hline
\end{tabular}

\section{Discussion}

In this study, UCA 1 and MALAT1 InCRNA in ESCC tissues were found to have increased expression levels compared to adjacent carcinoma tissues and were significantly correlated with TNM staging. The results of this study indicate that the expression levels of these two IncRNAs are up-regulated in ESCC tissues and may play important roles in ESCC pathogenicity.

The OS and DFS of patients with high expression of UCA1 and MALAT1 InCRNAs in ESCC tissues were found to be significantly lower than those of patients with low expression levels, suggesting that the high expression of these two types of IncRNA played a role in determining OS and DFS. The degree to which UCA1 and MALAT1
IncRNAs changed in ESCC tissues was associated with the progression of the tumors and the patient's postoperative survival, suggesting that the expression of these IncRNAs might be used as auxiliary indicators to evaluate tumor progression and prognosis.

Relevant studies have revealed that UCA1 can promote the expression of WNT6 and inhibit the expression of the p27 gene, and it can influence the stage of tumor cells through the PI3K/Akt signaling pathway to exert cancer-promoting effects on proliferation and apoptosis in a variety of cancer types $[19,20]$. UCA1 can also regulate the expression of tumor drug resistance genes [21, 22], giving it the ability to enhance the proliferation, infiltration, and migration of ESCC cells and lower the sensitivity to anti-tumor drugs. Our results 
support previous studies suggesting that measuring UCA1 expression could be a target for the treatment of ESCC and the evaluation of patient condition [23].

MALAT1 can react with multiple proteins in the cell nucleus to influence gene regulation and cancer cell movement capability [24]. Previous studies have found that the inhibition of MALAT1 can up-regulate the expression of caspase-8, caspase- 3 and Bax, and down-regulate the expression of $\mathrm{BCl}-2$ and $\mathrm{BCl}-\mathrm{xL}$, all of which were related to the development $\operatorname{ESCC}[25,26]$. The expression of MALAT1 in ESCC tissues at the middle-advanced stage has been found to be higher than that at the early stage, and the amplitude of the up-regulation is associated with the progression of tumor TNM staging and lymph node metastasis, suggesting that the inhibition of MALAT1 could stagnate the proliferation of ESCC tumor cells [27]. Therefore, abnormal expression of MALAT1 in malignant tumor tissues and its involvement with cell cycle stage make it a potential target for the treatment of ESCC [28].

In conclusion, we found that the expression of UCA1 and MALAT1 IncRNAs is up-regulated in ESCC tissues and that their expression can impact the degree of tumor progression. This in turn impacts patients' postoperative survival time and can serve as an auxiliary index for predicting the prognosis of ESCC patients. Both IncRNAs are potential targets for ESCC treatments, and future studies will investigate the feasibility of interfering with their expression in a clinical setting.

\section{Conflict of interest}

The authors declare no conflict of interest.

\section{References}

1. Zhang Y. Epidemiology of esophageal cancer. World J Gastroenterol 2013; 19: 5598-606.

2. Diakowska D, Markocka-Maczka K, Nienartowicz M, et al. Increased level of serum prostaglandin-2 in early stage of esophageal squamous cell carcinoma. Arch Med Sci 2014; 10: 956-61.

3. Zhang J, Jiang Y, Wu C, et al. Comparison of clinicopathologic features and survival between eastern and western population with esophageal squamous cell carcinoma. J Thorac Dis 2015; 7: 1780-6.

4. Takada A, Nakamura T, Takayama K, et al. Preliminary treatment results of proton beam therapy with chemoradiotherapy for stage I-III esophageal cancer. Cancer Med 2016; 5: 506-15.

5. Han D, Yuan Y, Song X, et al. What is the appropriate clinical target volume for esophageal squamous cell carcinoma? Debate and consensus based on pathological and clinical outcomes. J Cancer 2016; 7: 200-6.

6. Cheng C, Zhou Y, Li H, et al. Whole-genome sequencing reveals diverse models of structural variations in esophageal squamous cell carcinoma. Am J Hum Genet 2016; 98: 256-74.
7. Sen R, Ghosal S, Das S, et al. Competing endogenous RNA: the key to posttranscriptional regulation. Sci World J 2014; 2014: 896206.

8. Pan $F$, Yao J, Chen Y, et al. A novel long non-coding RNA FOXCUT and mRNA FOXC1 pair promote progression and predict poor prognosis in esophageal squamous cell carcinoma. Int J Clin Exp Pathol 2014; 7: 2838-49.

9. Yoon JH, Abdelmohsen K, Gorospe M. Functional interactions among microRNA and long noncoding RNAs. Semin Cell Dev Biol 2014; 34: 9-14.

10. Geisler S, Coller J. RNA in unexpected places: long noncoding RNA functions in diverse cellular contexts. Nat Rev Mol Cell Biol 2013; 14: 699-712.

11. Mitra SA, Mitra AP, Tfiche TJ. A central role for long non-coding RNA in cancer. Genetics 2012; 3: 17.

12. Guo JC, Li CQ, Wang OY, et al. Protein-coding genes combined with long non-coding RNAs predict prognosis in esophageal squamous cell carcinoma patients as a novel clinical multi-dimensional signature. Mol Biosyst 2016; 12: 3467-77.

13. Yao J, Huang JX, Lin M, et al. Microarray expression profile analysis of aberrant long non-coding RNAs in esphageal squamous cell carcinoma. Int J Oncol 2016; 48: 2543-57.

14. Li JY, Ma X, Zhang CB. Overexpression of long non-coding RNA UCA1 predicts a poor prognosis in patients with esophageal squamous cell carcinoma. Int I Clin Exp Pathol 2014; 7: 7938-44.

15. Zhou XL, Wang WW, Zhu WG, et al. High expression of long-coding RNA AFAP1-AS1 predicts chemoradioresistance and poor prognosis in patients with esophageal squamous cell carcinoma treated with definitive chemoradiotherapy. Mol Carcinog 2016; 55: 2095-105.

16. Hu L, Wu Y, Tan D, et al. Up-regulation of long noncoding RNA MALAT1 contributes to proliferation and metastasis in esophageal squamous cell carcinoma. J Exp Clin Cancer Res 2015; 34: 7.

17. Wang X, Li M, Wang Z, et al. Silencing of long noncoding RNA MALAT1 by miR-101 and miR-217 inhibits proliferation, migration, and invasion of esophageal squamous cell carcinoma cells. J Biol Chem 2015; 290: 3925-35.

18. Wang W, Zhu Y, Li S, et al. Long noncoding RNA MALAT1 promotes malignant development of esophageal squamous cell carcinoma by targeting b-catenin via Ezh2. Oncotarget 2016; 7: 25668-82.

19. Huang J, Zhou N, Watabe K, et al. Long non-coding RNA UCA1 promotes breast tumor growth by suppression of p27 (Kip1). Cell Death Dis 2014; 5: e1008.

20. Fang Z, Wu L, Wang L, Yang Y, Meng Y, Yang H. Increased expression of the long non-coding RNA UCA1 in tongue squamous cell carcinomas: a possible correlation with cancer metastasis. Oral Surg Oral Med Oral Pathol Oral Radiol 2014; 117: 89-95.

21. Han Y, Yang YN, Yuan HH, et al. UCA1, a long non-coding RNA up-regulated in colorectal cancer influences cell proliferation, apoptosis and cell cycle distribution. Pathology 2014; 46: 396-401.

22. Li Z, Li X, WU S, Xue M, Chen W. Long non-coding RNA UCA1 promotes glycolysis by upregulating hexokinase 2 through the Mtor-STAT3/microRNA143 pathway. Cancer Sci 2014; 105: 951-5.

23. Li JY, Ma X, Zhang CB. Overexpression of long non-coding RNA UCA1 predicts a poor prognosis in patients with esophageal squamous cell carcinoma. Int J Clin Exp Pathol 2014; 7: 7938-44.

24. Schmidt LH, Spieker T, Koschmieder S, et al. The long noncoding RNA MALAT1 indicates a poor prognosis in 
non-small cell lung cancer and induces migration and tumor growth. J Thorac Oncol 2011; 6: 1984-92.

25. Gutschner T, Diederichs S. The hallmarks of cancer: a long noncoding RNA point of view. RNA Biol 2012; 9: 703-19.

26. Ren S, LiuY, Xu M, et al. Long non-coding RNA MALAT1 is a new potential therapeutic target for castration resis tant prostate cell. J Urol 2013; 190: 2278-87.

27. Gutsehner T, Hammerle M, Eissmanm M, et al. The noncoding RNA MALAT1 is acritical regulator of the metas tasis phenotype of lung cancer cells. Cancer Res 2013; 73: 1180-9

28. Cao X, Zhao R, Chen Q, et al. MALAT1 might be a predictive marker of poor prognosis in patients who un derwent radical resection of middle thoracic esophageal squamous cell carcinoma. Cancer Biomark 2015; 15 717-23. 